\title{
A Systematic Literature Review of the Association of Lipoprotein(a) and Autoimmune Diseases and Atherosclerosis
}

\author{
I. Missala, U. Kassner, and E. Steinhagen-Thiessen \\ Department of Lipid Disorder, Charité University Medical Department in Berlin, Berlin, Germany \\ Correspondence should be addressed to I. Missala, isabelle.missala@charite.de
}

Received 13 January 2012; Revised 5 July 2012; Accepted 5 September 2012

Academic Editor: Jane Worthington

Copyright () 2012 I. Missala et al. This is an open access article distributed under the Creative Commons Attribution License, which permits unrestricted use, distribution, and reproduction in any medium, provided the original work is properly cited.

Objective. To investigate the association of lipoprotein(a) and atherosclerosis-related autoimmune diseases, to provide information on possible pathophysiologic mechanisms, and to give recommendations for $\mathrm{Lp}$ (a) determination and therapeutic options. Methods. We performed a systematic review of English language citations referring to the keywords "Lp(a)" AND "autoimmune disease" AND "atherosclerosis," "Lp(a)" AND “immune system" OR “antiphospholipid (Hughes) syndrome (APS)" OR "rheumatoid arthritis" OR "Sjögren's syndrome" OR "systemic lupus erythematosus" OR "systemic sclerosis" OR "systemic vasculitis" published between 1991 and 2011 using Medline database. Results. 22 out of 65 found articles were identified as relevant. $\mathrm{Lp}$ (a) association was highest in rheumatoid arthritis (RA), followed by systemic lupus erythematosus (SLE), moderate in APS and lowest in systemic sclerosis (SSc). There was no association found between Lp(a) and systemic vasculitis or Sjögren's syndrome. Conclusion. Immune reactions are highly relevant in the pathophysiology of atherosclerosis, and patients with specific autoimmune diseases are at high risk for CVD. Elevated $\mathrm{Lp}(\mathrm{a})$ is an important risk factor for premature atherosclerosis and high $\mathrm{Lp}(\mathrm{a})$ levels are also associated with autoimmune diseases. Anti-Lp(a)-antibodies might be a possible explanation. Therapeutic approaches thus far include niacin, Lp(a)-apheresis, farnesoid x-receptor-agonists, and CETP-inhibitors being currently under investigation.

\section{Introduction}

Atherosclerosis is a major cause of cardiovascular disease (CVD). Autoimmune reactions and inflammation are mainly involved in their pathogenesis. Already at early onset atherosclerosis inflammatory cells (monocytes, macrophages, dendritic cells, T- and B-cells) and cytokines can be identified in the lesion area and those cells may provoke cellmediated immune reactions (CMIR) that (i) modulate the development of atherosclerosis and may (ii) predetermine its progression $[1,2]$. Immune reactions may modulate atherosclerosis in different ways: (i) $\beta 2$ glycoprotein Iimmunization led to an increase, (ii) heat shock protein (HSPs) 60/65 antigen led to an increase, and (iii) oxLDLimmunization led to a decrease $[3,4]$. In addition to established risk factors of CVD, autoimmune processes are discussed as being highly relevant. Autoimmune disorders are associated with a high CVD risk in clinical practice. In a major autoimmune disease, SLE, animal studies identified mainly proinflammatory Th1 cytokines (e.g., IFN-gamma), whereas in humans with SLE mainly Th2 cytokines were identified as involved in CMIR [3]. Risk factors for CVD in SLE are enhanced atherosclerosis, increased inflammation, elevated levels of oxidized LDL (oxLDL) and autoantibodies against oxLDL, increased triglycerides, total cholesterol (TC) and $\operatorname{Lp}(\mathrm{a})$ and decreased HDL-cholesterol, raised systemic inflammation and the presence of anti-phospholipid antibodies (aPL), high homocysteine levels, and osteoporosis [2]. But the relative risk of CVD differs among the specific autoimmune disease. Some autoimmune disorders like systemic lupus erythematosus (SLE), rheumatoid arthritis, antiphospholipid (Hughes) syndrome (APS), and systemic sclerosis carry a high risk of CVD development, whereas others as the Sjögren's syndrome and systemic vasculitis seem to have a weaker influence on CVD development.

$\mathrm{Lp}$ (a) remains an important risk factor for premature atherosclerosis and CVD development. It was first mentioned by Berg, K 1963 [5] and contains an LDL-like particle with apolipoprotein B-100 (apoB 100) linked to apolipoprotein(a) $(\operatorname{apo}(a)) \cdot \operatorname{Lp}(a)$ distribution in population is lowest 
TABLE 1: Exclusion and inclusion criteria of review.

\begin{tabular}{ll}
\hline Exclusion & Inclusion \\
\hline $\begin{array}{l}\text { Unrelated to topical Lp(a) and autoimmune disease and } \\
\text { atherosclerosis and CVD considered as not relevant }\end{array}$ & $\begin{array}{l}\text { Autoimmune disorders: antiphospholipid (Hughes) syndrome } \\
\text { (APS), rheumatoid arthritis, Sjögren's syndrome, systemic lupus } \\
\text { erythematosus, systemic sclerosis, and systemic vasculitis }\end{array}$ \\
$\begin{array}{l}\text { Unpublished studies } \\
\text { Pingle case studies }\end{array}$ & \\
Available not as full text (reprints were requested) & \\
Dissertations or theses or book chapters & \\
\hline
\end{tabular}

in Caucasians, modest in Hispanics, Chinese, Japanese, and highest in Blacks [6]. Multiple existing genetic variations and polymorphisms of apo(a) cause variations in population $\mathrm{Lp}$ (a) plasma levels. $\mathrm{Lp}(\mathrm{a})$ is involved in atherosclerosis in different ways: (i) it accumulates in the arterial intima and (ii) it activates inflammatory cells and (iii) binds to proinflammatory-oxidized-phospholipids [7, 8]. It additionally promotes thrombosis and inhibits fibrinolysis due to the high structural homology between apo(a) and plasminogen $[8,9]$. It is secreted by the liver and undergoes renal and hepatic metabolism.

There is evidence that serum $\operatorname{Lp}(\mathrm{a})$ and LDL can act additively in the development of coronary heart disease. $\mathrm{Lp}$ (a) undergoes oxidative modification like oxLDL [10] and provokes an immune response [11]. It enters the arterial wall via a macrophage scavenger receptor [12] - a known pathway for ox-LDL. Ox-LDL-formation induces the production of anti-ox-LDL-antibodies, and a similar mechanism is suggested for $\operatorname{ox}-\operatorname{Lp}(\mathrm{a})[11,13]$. These autoantibodies have been found in atherosclerotic lesions [14]. Furthermore, antibodies against ox-LDL and ox-Lp(a) are more prevalent in patients with specific autoimmune diseases $[11,15,16]$.

$\mathrm{Lp}(\mathrm{a})$ is involved in immunological processes and several studies showed a high association with some autoimmune diseases. Mechanisms mainly involved in this association are HLA-genotype-predominance, Lp(a)-autoantibodies, the relation of fibrinolytic system parameters and $\operatorname{Lp}(\mathrm{a})$, the relation of acute phase system parameters and $\operatorname{Lp}(\mathrm{a})$, and the complex formation of beta(2)-GPI-Lp(a).

Our aim was to show that patients with specific autoimmune disorders have a higher atherosclerosis risk which might be aggravated by elevated Lp(a) levels. The measurement of $\operatorname{Lp}(\mathrm{a})$ levels might be an additional tool to identify patients at high risk for CVD.

\section{Methods}

2.1. Search Strategy. A systematic literature research was conducted consulting the Medline database PUBMED using the following keywords: "Lp(a)" AND "autoimmune disease" AND "atherosclerosis," "Lp(a)" AND “immune system," "Lp(a)" AND "antiphospholipid (Hughes) syndrome (APS, )" "Lp(a)" AND "rheumatoid arthritis," "Lp(a)" AND "Sjogren's syndrome," "Lp(a)" AND "systemic lupus erythematosus," "Lp(a)" AND "systemic sclerosis," "Lp(a)" AND "systemic vasculitis."
2.2. Selection Criteria. Titles and abstracts were excluded (Table 1) if they were (i) unrelated to topical Lp(a) and autoimmune disease and atherosclerosis or CVD, (ii) not written in English, (iii) unpublished studies, (iv) only available as abstracts and not as full-text articles (reprints were requested), (v) theses or book chapters, (vi) investigations published in nonpeer-reviewed journals, (vii) single case studies, and (viii) highly specific articles not considered as relevant in this context.

2.3. Manual Review. All full-text articles were read by two independent reviewers and rated as "relevant" or "not relevant" in this context. Additionally a search of secondary sources as articles references was committed.

\section{Results}

The initial search yielded 67 citations, there were 25 articles for "Lp(a)" AND "rheumatoid arthritis," 20 for "systemic lupus erythematosus," 4 for "immune system," 11 for "APS," 3 for "systemic sclerosis", and 4 for "autoimmune disease." The literature research showed no citations for the keywords "systemic vasculitis" and "Sjögren's syndrome." Thirteen citations (Frostegard, Sari, Romero 2000 (3), Zhang 2011, Atsumi, Sakata) were duplicates. From the remaining 61 citations 32 met our inclusion criteria and were identified as relevant. 27 articles were excluded, because of earlier publication date (2), no full text (FT) available (3), other autoimmune diseases (6), investigation of children only (2), sex specific investigations (3), other diseases but atherosclerosis and $\mathrm{CHD}$ and other autoimmune diseases (11). Figure 1 shows a flowchart of the systematic review process.

3.1. Lp (a) and Systemic Sclerosis (SSc). SSc is an autoimmune disorder characterized by excessive production of collagen, fibronectin, and other matrix proteins which accumulate in the skin and internal organs with resulting thrombosis [17]. Abnormally high $\mathrm{Lp}$ (a) levels are found in SSc patients leading to defective fibrinolysis and a hypercoagulable state [18] - endothelial injury worsens the situation even more. Ames et al. [17] showed significantly elevated Lp(a) levels in SSc patients versus controls resulting in a hypercoagulable state with elevated plasma levels of fibrinogen and von Willebrandt Factor (VWF) due to (i) defective tissue plasminogen activator (tPA) release and (ii) increased tPA inhibitor concentrations and (iii) by increased thrombin generation 


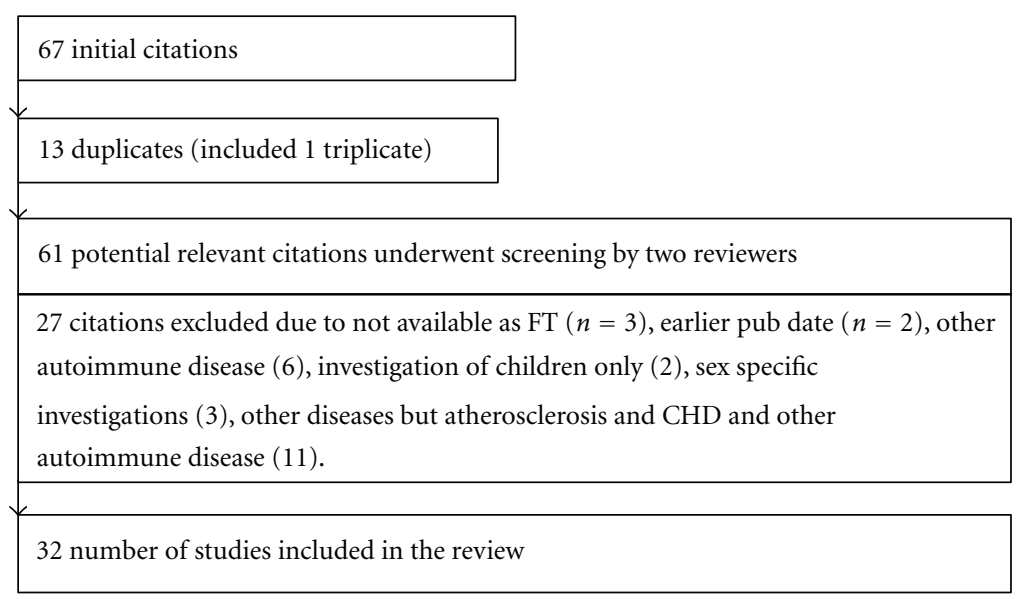

Figure 1: Systematic review process.

with enhanced fibrin formation. A possible explanation is that apo(a) has high sequence homology with plasminogen. It might compete with $\mathrm{tPA}$ for fibrin binding and therefore weakens fibrinolysis [19].

Lippi et al. [20] showed statistically significant differences in SSc patients when compared to healthy controls in $\mathrm{Lp}(\mathrm{a})$ levels. They concluded that $\operatorname{Lp}(\mathrm{a})$ measurement might be useful in SSc to identify and eventually treat subsets of patients more predisposed to develop thrombotic complications.

3.2. $L p(a)$ and Rheumatoid Arthritis (RA). RA is a chronic, systemic, inflammatory disorder that primarily involves joints. It is a polyarticular disease with a gradual onset, intermittent or migratory joint involvement, and a monoarticular onset are different types of clinical presentations of RA. In addition, extra-articular manifestations may be present.

Higher $\mathrm{Lp}(\mathrm{a})$ levels are found in RA patients when compared to healthy controls. Asanuma et al. [21] showed significantly higher $\operatorname{Lp}(\mathrm{a})$ values in RA patients compared to controls. Additionally they showed a high predominance of the S3 allele and concluded causality. Lee et al. [22] found elevated Lp(a) levels in RA patients compared to controls as well. Although $\operatorname{Lp}(\mathrm{a})$ tended to be higher in RA, they could not find a distinct acute phase pattern of $\operatorname{Lp}(\mathrm{a})$. Their data support the phenomenon that dyslipoproteinemia observed in RA is associated with inflammation. Dursuno et al. [23] showed a positive correlation between $\mathrm{Lp}(\mathrm{a})$ and CPR level and a negative correlation between $\mathrm{Lp}(\mathrm{a})$ and HDL level in RA patients. They concluded that infammationa processes in RA patients my cause both changes in $\mathrm{Lp}(\mathrm{a})$ and HDL$\mathrm{C}$ metabolism. Wang et al. [24] reported that $\mathrm{Lp}(\mathrm{a})$ and ox$\mathrm{Lp}$ (a) concentrations in active RA were higher than those in both inactive RA and control; Lp(a)-immune complex (IC) concentrations in active RA were also higher than inactive $\mathrm{RA}$, while no difference was found in $\operatorname{Lp}(\mathrm{a}), \operatorname{ox}-\mathrm{Lp}(\mathrm{a})$, and $\mathrm{Lp}(\mathrm{a})$-IC concentrations between inactive RA and controls. $\operatorname{Lp}(\mathrm{a})$, ox-Lp(a), and $\operatorname{Lp}(\mathrm{a})-\mathrm{IC}$ were all found positively related with elevated C-reactive protein (CRP) levels and erythrocyte sedimentation rate (ESR), respectively. The study results underline the role of $\operatorname{Lp}(\mathrm{a})$ as acute phase protein.
Kerekes et al. [25] discovered low flow mediated dilatation (FMD) and high Carotid intima-media-thickness (ccIMT) in RA patients and a correlation of $\mathrm{Lp}(\mathrm{a})$ in RAassociated atherosclerosis. They suggest the evaluation of FMD\% and ccIMT as useful tool to assess RA patients with high cardiovascular risk.

Zhang et al. [26] showed a complex formation of beta(2)-glycoprotein I (beta(2)-GPI) with $\mathrm{Lp}(\mathrm{a})$ in patients with active RA. Inflammation and oxidative stress in RA contribute to the increase of $\operatorname{ox}-\operatorname{Lp}(\mathrm{a})$ and subsequently the formation of $\operatorname{beta}(2)-G P I-L p(a)$. Beta(2)-GPI-Lp(a) and beta(2)-GPI-ox-LDL complex concentrations increased in RA patients and may be useful in assessing the development of atherosclerosis in patients with autoimmune diseases. Inflammation and oxidative stress may result in increased ox$\mathrm{Lp}$ (a) and ox-LDL, and subsequently the formation of the complexes of beta(2)-GPI-Lp(a) and beta(2)-GPI-ox-LDL.

3.3. Lp (a) and Systemic Lupus Erythematosus (SLE). SLE is a classic autoimmune disease characterized by the production of autoreactive $\mathrm{T}$ cells and autoantibodies that may affect multiple organ systems. SLE patients were found to have elevated serum $\mathrm{Lp}$ (a) levels compared to healthy controls in several studies [15-17], and developed preferably myocardial infarction [18]. Premature atherosclerosis and coronary artery disease (CAD) in SLE-disorder have been reported as major cause of mortality.

The risk of CVD development in SLE-patients is very high, SLE-related CVD is a common phenomenon. The risk factors for CVD in SLE include [2] atherosclerosis (ccIMT), raised oxLDL and autoantibodies to oxLDL, combined dyslipidemia with high triglyceride and low HDL, Lp(a), raised systemic inflammation, presence of anti-phospholipid antibodies including lupus anticoagulant, homocysteinelevels, and more frequent osteoporosis. Sari et al. [3] showed in their investigation that SLE patients have a risk of developing coronary artery disease which is associated with high levels of serum TC and Lp(a) and low levels of HDL-C and apo A-I.

McMahon et al. [27] showed that high leptin levels greatly increase the risk of subclinical atherosclerosis in SLE 
and are also associated with an increase in inflammatory biomarkers of atherosclerosis such as HDL, Lp(a), and oxPL/apoB100. High leptin levels may help to identify patients with SLE at risk of atherosclerosis. Zhang et al. [28] reported about the existence of beta(2)-GPI-Lp(a) complexes in both controls and SLE patients. The complexes levels are increased in SLE patients.

There was high association between elevated $\mathrm{Lp}(\mathrm{a})$ and lupus erythematosus with renal involvement [29]-lupus nephritis was shown in 30 patients [30] compared to SLEpatients without renal failure. $\operatorname{Lp}(\mathrm{a})$ was increased in patients with proteinuria [31]. Several studies revealed a positive correlation between serum $\operatorname{Lp}(\mathrm{a})$ and serum cholesterol and urinary protein levels, and an inverse correlation between $\mathrm{Lp}(\mathrm{a})$ and albumin levels [3, 32, 33]. For patients with lupus anticoagulant besides the elevated $\mathrm{Lp}(\mathrm{a})$ a higher concentration of activated factor VII (FVIIa) was shown worsening the prothrombotic state of the disease [34]. Systemic lupus erythematosus patients had higher leptin levels, and there was a significant correlation between leptin level and $\mathrm{Lp}(\mathrm{a})$ [27].

3.4. Lp(a) and Antiphospholipid Syndrome (APS). Antiphospholipid syndrome (APS) is an autoimmune disease characterized by arterial and/or venous thrombosis and recurrent abortions, accompanied by elevated titers of antiphospholipid antibodies [35]. Significantly higher plasma levels of $\mathrm{Lp}(\mathrm{a})$ are found in patients with APS [36-38]. Kritz et al. [39] demonstrated an association in patients with antiphospholipid syndrome as well as those with lack in the prostacyclin synthesis stimulating plasma factor $(\mathrm{PF})$ and $\mathrm{Lp}(\mathrm{a})$, indicating a biochemical interaction.

Romero et al. [13] demonstrated the existence of autoantibodies against malondialdehyde (MDA)-Lp(a) in APS. The presence of antibodies reacting not only against MDA-LDL but also against MDA-Lp(a) supports the hypothesis of a role for oxidative phenomena in the pathogenesis of APS and atherosclerosis.

Yasuda et al. [40] focussed on the association of beta(2)-GPI and lipoprotein metabolism in APS patients, they showed individuals with heterozygous beta(2)-GPI deficiency showed significantly lower concentrations of serum beta(2)-GPI, but no significant influence on lipid metabolism was found.

López Lira [41] mentioned in their study that the interference in the plasmin conversion by anti-beta2GPI antibodies could generate thrombosis as observed in APS.

Bećarević et al. [38] investigated the appearance of recurrent cardio- and cerebrovascular events in patients with APS. They showed that only patients with stroke had a recurrence of cerebrovascular episodes (this was not shown for patients with myocardial infarction). Their conclusion was that measurement of apo(a) concentrations will help in the followup of those patients and thus in the prediction of future episodes.

Table 2 shows the design characteristics and Key messages of the included studies.

\section{Discussion}

This structured, systematic literature review identified 22 relevant studies related to the association of $\operatorname{Lp}(\mathrm{a})$ with specific atherosclerosis-related autoimmune diseases. Most of the investigations were randomized controlled trials with patients suffering from one specific autoimmune disease, there were just few reviews focusing on the association of atherosclerosis and immune system/autoimmune disorder in general.

Objectives of interest were HLA-genotype-predominance, $\mathrm{Lp}(\mathrm{a})$-autoantibodies, relation of fibrinolysis system parameters and $\operatorname{Lp}(\mathrm{a})$, relation of acute phase system parameters and $\mathrm{Lp}(\mathrm{a})$, and complex formation of beta(2)-GPI$\mathrm{Lp}(\mathrm{a})$ and $\mathrm{Lp}(\mathrm{a})$-apheresis. In general study results were concurrent in their overall message highlighting the occurrence of elevated $\mathrm{Lp}(\mathrm{a})$ levels in active autoimmune disease. All articles emphasized the influence of autoimmune mechanism on lipid metabolism esp. the occurrence of oxLDL and ox- $\mathrm{Lp}(\mathrm{a})$. Oxidation of LDL and $\mathrm{Lp}(\mathrm{a})$ is postulated to play a key role in the early initiation of atherosclerosis. Also changes in lipoproteins due to glycosylation, like the formation of beta(2)-GPI-Lp(a) [26] which were first detected in patients with RA and APS [28, 40, 41], and then in patients with CAD [42], might lead to early atherosclerosis.

Apart from its proatherogenic potential $\mathrm{Lp}(\mathrm{a})$ has also thromboembolic properties due to the structural analogy of apo(a) and plasminogen. In SSc patients $\mathrm{Lp}(\mathrm{a})$ directly weakened the fibrinolytic process by competition with tPA for fibrin binding leading to clinical apparent increased risk and occurrence of thrombosis [17]. We assume that in clinical practice in SSc patients $\operatorname{Lp}(\mathrm{a})$ level should be measured to evaluate their thrombosis risk and initiate a sufficient preventive treatment.

Furthermore Lp(a) elevation merges with acute-phaseprotein increase. In RA patients $\mathrm{Lp}(\mathrm{a})$ was associated with elevated CRP-level and erythrocyte sedimentation rate (ESR) and therefore playing an important role in the acute phase cascade reaction process [23] $\mathrm{Lp}(\mathrm{a})$ is claimed to react as acute phase protein in other diseases as well esp. ischemic stroke [43] vestibular neuronitis [44], in patients on chronic haemodialysis [45, 46] and polymyalgia rheumatica [47].

The impact of glycosylation in atherosclerosis development with complex formation of beta(2)-GPI with Lp(a) mentioned above was shown for RA patients. Wang et al. [24] investigated the association of $\operatorname{Lp}(\mathrm{a})$-beta(2)-GPI-complexes and coronary artery disease; they showed that ox-Lp(a) was a risk factor only for acute coronary syndrome, while not for stable coronary artery disease. Beta(2)-GPI-Lp(a) levels were found to be positively associated with $\operatorname{Lp}(\mathrm{a}), \operatorname{ox}-\mathrm{Lp}(\mathrm{a})$, maximal stenosis, and a number of vascular diseases in patients with ACS or stable CAD, respectively. They suggest that high levels of beta(2)-GPI-Lp(a) are associated with the presence and severity of CAD and may be a strong risk factor for atherosclerosis. An association in APS patients was shown as well [40]. This should be object of further research.

The formation of autoantibodies towards $\mathrm{Lp}(\mathrm{a})$ seems to be triggered by autoimmune diseases. Anti-malondialdehyde (MDA)-Lp(a) were detected in patients with APS syndrome 
TABLE 2: Design characteristics and messages of included studies.

\begin{tabular}{|c|c|c|}
\hline Objective & Reference & Results \\
\hline APS & Kritz et al. 1996 [39] & $\begin{array}{l}\text { All patients with a deficient PF activity had high } \mathrm{Lp}(\mathrm{a}) \text { values. While the prevalence } \\
\text { of PF deficiency ranges about } 1-2 \% \text {, in } 7(19 \%) \text { patients with clinically manifested } \\
\text { atherosclerosis and } 3(19 \%) \text { healthy adults with elevated } \mathrm{Lp}(\mathrm{a}) \text { this defect was } \\
\text { found. The findings demonstrate an association between PF deficiency and } \mathrm{Lp}(\mathrm{a}) \text {, } \\
\text { indicating a biochemical interaction. }\end{array}$ \\
\hline APS & Yasuda et al. 2000 [40] & $\begin{array}{l}\text { A low concentration of beta(2)-GPI seemed not to be associated with apparent } \\
\text { abnormality in lipoprotein metabolism. }\end{array}$ \\
\hline APS & Bećarević et al. 2007 [38] & $\begin{array}{l}\text { PAPS patients with cerebrovascular insults had recurrence of cerebrovascular } \\
\text { episodes, measurement of apo(a) concentrations will help in the follow-up of those } \\
\text { patients and thus in the prediction of future episodes. }\end{array}$ \\
\hline $\begin{array}{l}\text { APS } \\
\text { SLE }\end{array}$ & Atsumi et al. 1998 [36] & $\begin{array}{l}\text { Elevated plasma levels of } L p(a) \text { were found in patients with APS compared to } 22 \\
\text { healthy controls }(P=0.0001) \text {. Patients with APS with maximal elevation of } L p(a) \\
\text { showed a lower fibrinolytic activity (lower D-dimer and higher plasminogen } \\
\text { activator inhibitor) than patients whose } L p(a) \text { was within a normal range. These } \\
\text { findings suggest that } L p(a) \text { may represent a marker of APS and that Lp(a) has a } \\
\text { negative effect on the fibrinolytic system that might contribute to the thrombotic } \\
\text { tendency of APS. }\end{array}$ \\
\hline
\end{tabular}

Existence of autoantibodies against MDA-Lp(a). The presence of antibodies

APS Romero eta al. 1999 [13] reacting not only against MDA-LDL but also against MDA-Lp(a) supports the hypothesis of a role for oxidative phenomena in the pathogenesis of APS and atherosclerosis.

A number of factors can be encountered in the pathogenesis of the accelerated arterial disease seen in patients with antiphospholipid (Hughes) syndrome (APS)

APS

SLE

immune

Romero et al. 2000 [11]

López-Lira et al. 2006 [41]

APS $\quad$ Yamazaki et al. 1994 [37]

RA Asanuma et al. 1999 [21]

RA

Busso et al. 2001 [61]

RA

Cesur et al. 2007 [62]

RA

Dahlén 1994 [48] and systemic lupus erythematosus (SLE). Among these, high levels of Lp(a) have been described in both and increasing evidence indicates that patients with antiphospholipid antibodies (aPL) are under oxidative stress. Recent studies suggest that the so-called "oxidation theory of atherosclerosis" may also be applied to $\mathrm{Lp}(\mathrm{a})$.

Beta2-glycoprotein I (beta2GPI) is a glycoprotein of unknown physiological function. It is the main target antigen for antiphospholipid antibodies in patients with antiphospholipid syndrome (APS). beta2GPI binds with high affinity to the atherogenic lipoprotein $\mathrm{Lp}(\mathrm{a})$ which shares structural homology with plasminogen, a key molecule in the fibrinolytic system. Impaired fibrinolysis has been described in APS.

Patients with aPL are in hypercoagulable state. High levels of Lp(a) in plasma may impair the fibrinolytic system resulting in thromboses, especially in the arterial system.

The mean serum Lp(a) level was significantly higher $(P<0.001)$ in the RA patients $(27.5 \mathrm{mg} / \mathrm{dL})$ than in the controls $(15.0 \mathrm{mg} / \mathrm{dL})$ possibly partly because of S3 phenotype predominance.

These data indicated that synovial fluid apo(a) originates from circulating $\operatorname{Lp}(\mathrm{a})$ and that diffusion of $\operatorname{Lp}(\mathrm{a})$ through synovial tissue is facilitated in inflammatory types of arthritis. In synovial tissues, apo(a) co-localized with fibrin. In humans, apo(a) may modulate locally the fibrinolytic activity and may thus contribute to the persistence of intra-articular fibrin in inflammatory arthritis.

Analysis of the six studies showed Lp(a) level was higher and HDL level was lower in RA patients than in healthy controls. Patients with RA may have altered lipid profiles from one country to another one. Especially in Turkey, higher serum Lp(a), lower HDL-C and higher TG levels may be found in RA patients instead of some findings of other countries showing different results. Ethnicity may be a reason for these findings.

In this paper additional results of interleukin determinantions in relation to HLA type and $\mathrm{Lp}(\mathrm{a})$ levels are presented and discussed. It is suggested that an autoimmune process, perhaps triggered by a concomitant intracellular infection may occur, especially in patients with inherited high $\mathrm{Lp}(\mathrm{a})$ levels in combination with certain inherited HLA class II genotypes. 
Table 2: Continued.

\begin{tabular}{|c|c|c|}
\hline Objective & Reference & Results \\
\hline RA & Dahlén 1994 [48] & $\begin{array}{l}\text { The associations found between } \mathrm{LP}(\mathrm{a}) \text { and insulin release, rheumatoid arthritis and } \\
\text { renal diseases suggest that } \mathrm{Lp}(\mathrm{a}) \text { may be involved in immunological mechanisms. In } \\
\text { a new hypothesis it is suggested that an autoimmune process might especially occur } \\
\text { in individuals with inherited high } \mathrm{Lp}(\mathrm{a}) \text { levels and certain HLA class II genotypes, } \\
\text { triggered by a concurrent infection. }\end{array}$ \\
\hline RA & Wållberg-Jonsson et al. 1995 [47] & $\begin{array}{l}\text { Certain HLA class II DR genotypes in combination with high Lp (a) levels and C. } \\
\text { pneumoniae titers occurred more frequently in both male and female patients than } \\
\text { in controls. }\end{array}$ \\
\hline RA & Dursunoğlu et al. 2005 [23] & $\begin{array}{l}\text { In the RA and control groups, serum } \mathrm{Lp}(\mathrm{a}) \text { levels were } 39.2 \pm 20.6 \mathrm{mg} / \mathrm{dL} \text { and } \\
14.8 \pm 9.7 \mathrm{mg} / \mathrm{dL} \text {, respectively }(P<0.001) \text {. CRP levels were positively correlated } \\
\text { with } \mathrm{Lp}(\mathrm{a}), \mathrm{HDL}-\mathrm{C} \text { level were negatively correlated with } \operatorname{Lp}(\mathrm{a})(r=-0.36 \text {, } \\
P<0.001) \text {. }\end{array}$ \\
\hline RA & Zrour et al. 2011 [63] & $\begin{array}{l}\text { Sera of patients showed higher TC }(4.86 \pm 1.07 \text { versus } 3.98 \pm 0.73 \mathrm{mmol} / \mathrm{L} \text {, } \\
P<0.001), \mathrm{LDL}-\mathrm{c}(3.49 \pm 0.98 \text { versus } 1.99 \pm 0.62 \mathrm{mmol} / \mathrm{L}, P<0.001), \mathrm{Lp}(\mathrm{a}) \\
(288.04 \pm 254.59 \text { versus } 187.94 \pm 181.37 \mathrm{mmol} / \mathrm{L}, P=0.004) \text { and lower } \mathrm{HDL}-\mathrm{c} \\
(0.66 \pm 0.24 \text { versus } 1.12 \pm 0.3 \mathrm{mmol} / \mathrm{L}, P<0.001) \text {. Apo A- } 1 \text { was correlated to } \mathrm{Lp}(\mathrm{a}) \\
(r=0.291, P=0.005) \text {. Corticoid dose was not associated to dyslipidaemia, but in } \\
\text { multiple regression models, corticoid dose may be negatively related to some } \\
\text { atherogenic markers, in particular non-HDL-c. Tunisian patients with markedly } \\
\text { active RA experience substantially reduced serum HDL-c and increased TC, LDL-c } \\
\text { and Lp(a) concentrations as well as increased TC/HDL-c, LDL-c/HDL-c and } \\
\text { non-HDL-c/HDL-c ratios. }\end{array}$ \\
\hline RA & Lee et al. 2000 [22] & $\begin{array}{l}\text { Nine }(42.3 \%) \text { of } 21 \mathrm{RA} \text { patients and } 6(31.6 \%) \text { of } 19 \text { controls had high } \mathrm{Lp}(\mathrm{a}) \text { levels } \\
(>30 \mathrm{mg} / \mathrm{dL}) \text { and the } \mathrm{Lp}(\mathrm{a}) \text { level was higher in RA patients compared with controls } \\
(27.1 \pm 5.3 \text { versus } 19.0 \pm 4.2 \mathrm{mg} / \mathrm{dL}) \text { without significant difference }(P>0.05) \text {. }\end{array}$ \\
\hline RA & Park et al. 1999 [64] & $\begin{array}{l}\text { Our study suggests that patients with untreated active RA have altered lipoprotein } \\
\text { and apolipoprotein patterns that may possibly expose them to higher risk of } \\
\text { atherosclerosis. The inflammatory condition of RA may affect the metabolism of } \\
\text { HDL-cholesterol and apo Al. }\end{array}$ \\
\hline RA & $\begin{array}{l}\text { Rantapää-Dahlqvist et al. } 1997 \\
\text { [65] }\end{array}$ & $\begin{array}{l}\text { Lipoprotein }(\mathrm{a}),(\mathrm{Lp}(\mathrm{a})) \text {, an independent atherogenic factor, was significantly } \\
\text { increased in } 93 \text { patients with classical, seropositive rheumatoid arthritis of median } \\
\text { disease activity. In the patients with } \mathrm{Lp}(\mathrm{a}) \text { concentrations above the upper reference } \\
\text { value of } 480 \mathrm{mg} / \mathrm{L} \text { there was a significant correlation between } \mathrm{Lp}(\mathrm{a}) \text { and the } \\
\text { concentration of orosomucoid, erythrocyte sedimentation rate, and the platelet } \\
\text { count. }\end{array}$ \\
\hline RA & Schultz et al. 2010 [66] & $\begin{array}{l}\text { Inhibition of IL- } 6 \text { signalling improves insulin sensitivity in humans with } \\
\text { immunological disease suggesting that elevated IL- } 6 \text { levels in type } 2 \text { diabetic } \\
\text { subjects might be causally involved in the pathogenesis of insulin resistance. } \\
\text { Furthermore, our data indicate that inhibition of IL- } 6 \text { signalling decreases Lp(a) } \\
\text { serum levels, which might reduce the cardiovascular risk of human subjects. }\end{array}$ \\
\hline RA & Wang et al. 2008 [24] & $\begin{array}{l}\mathrm{Lp}(\mathrm{a}) \text { levels were highest in active RA } 259.01 \pm 148.96 \mathrm{mg} / \mathrm{dL}) \text { modest in controls } \\
(177.43 \pm 106.51 \mathrm{mg} / \mathrm{dL}) \text { and lowest in inactive } \mathrm{RA}(173.03 \pm 106.20 \mathrm{mg} / \mathrm{dL}) . \mathrm{Lp}(\mathrm{a}) \\
\text { concentrations were found positively correlated with ox- } \mathrm{Lp}(\mathrm{a})(R=0.37, \mathrm{~Pb} 0.001) \\
\text { and } \mathrm{Lp}(\mathrm{a})-\mathrm{IC}(R=0.39, \mathrm{~Pb} 0.001) \text { concentrations respectively. Ox-Lp }(\mathrm{a}) \\
\text { concentrations were also related with } \mathrm{Lp}(\mathrm{a})-\mathrm{IC} \text { concentrations }(R=0.64, \mathrm{~Pb} 0.001) \text {. }\end{array}$ \\
\hline $\begin{array}{l}\text { RA } \\
\text { SLE }\end{array}$ & Zhang 2011 [26] & $\begin{array}{l}\text { Serum beta(2)-GPI-Lp(a) }(1.12 \pm 0.25 \mathrm{U} / \mathrm{mL} \text { versus } 0.87 \pm 0.19 \mathrm{U} / \mathrm{mL}, P<0.0001) \\
\text { and beta(2)-GPI-ox-LDL }(1.01 \pm 0.20 \mathrm{U} / \mathrm{mL} \text { versus } 0.80 \pm 0.08 \mathrm{U} / \mathrm{mL}, P<0.0001) \\
\text { concentrations in RA were both significantly higher than those of controls. } \\
\text { Ox- } \mathrm{Lp} \text { (a) }(8.38 \pm 6.69 \mathrm{mg} / \mathrm{L} \text { versus } 5.49 \pm 4.31 \mathrm{mg} / \mathrm{L}, P<0.05) \text { and ox-LDL } \\
(0.68 \pm 0.65 \mathrm{mg} / \mathrm{L} \text { versus } 0.37 \pm 0.13 \mathrm{mg} / \mathrm{L}, P=0.001) \text { were also higher in RA than } \\
\text { in controls. }\end{array}$ \\
\hline Ssc & Cerinic 2003 [18] & $\begin{array}{l}\text { Coagulation was significantly activated in Ssc patients (increase in } \mathrm{F} 1+2, P<.001 \text {; } \\
\text { TAT, } P<0.01 \text {; and } \mathrm{Lp}(\mathrm{a}), P<0.05) \text {. Endothelial injury reduces endothelial } \\
\text { function, as suggested by impairment of fibrinolysis and activation of the } \\
\text { coagulative pathway. }\end{array}$ \\
\hline
\end{tabular}


TABle 2: Continued.

\begin{tabular}{|c|c|c|}
\hline Objective & Reference & Results \\
\hline SSc & Lippi et al. 2006 [20] & $\begin{array}{l}\text { SSc patients had statistically significant differences when compared to healthy } \\
\text { controls in median and } 25-75 \text { th percentile distribution of } \mathrm{Lp}(\mathrm{a})(110 \mathrm{mg} / \mathrm{L} \text {, } \\
51-389 \mathrm{mg} / \mathrm{L} \text { versus } 79 \mathrm{mg} / \mathrm{L}, 29-149 \mathrm{mg} / \mathrm{L} ; P=0.005) \text {. When compared to current } \\
\text { NCEP/AHA/ACC goals, the values distributions and the relative percentage of } \\
\text { patients with undesirable or abnormal vales were statistically different for Lp (a) } \\
\text { (29\% versus } 3 \% \text { ) and Hs-CRP ( } 42 \% \text { versus } 12 \%) \text { (both } P<0.001) . \mathrm{Lp}(\mathrm{a}) \\
\text { measurement might be useful in SSc to identify and eventually treat subsets of } \\
\text { patients more predisposed to develop thrombotic complications. }\end{array}$ \\
\hline $\begin{array}{l}\text { SLE } \\
\text { autoimmune } \\
\text { disease }\end{array}$ & Frostegård 2002 [2] & $\begin{array}{l}\text { AD patients (SLE) are at high risk of CVD. Nontraditional risk factors like OxLDL, } \\
\text { oxLDL autoantibodies, phospholipids, and inflammation could lead to new } \\
\text { therapeutic strategies and insight into disease mechanisms. }\end{array}$ \\
\hline SLE & Borba et al. 1994 [67] & $\begin{array}{l}\text { Lp(a) levels are significantly higher in patients with SLE and are not influenced by } \\
\text { disease activity, thrombosis, aCL, and steroid therapy. }\end{array}$ \\
\hline SLE & George et al. 1999 [68] & $\begin{array}{l}\text { Patients with SLE and venous thrombosis had higher levels of beta2GPI-IC when } \\
\text { compared with thrombosis-free patients or with healthy controls }(P<0.05) \text {. } \\
\text { Patients with higher Lp (a) levels }(>50 \mathrm{mg} / \mathrm{dL}) \text { possessed higher levels of } \\
\text { beta2GPI-IC as compared with patients with lower Lp(a) concentration } \\
(<20 \mathrm{mg} / \mathrm{dL})(P<0.05) .\end{array}$ \\
\hline SLE & Okawa-Takatsuji et al. 1996 [29] & $\begin{array}{l}\text { Our study is the first to reveal that hypoalbuminemia appearing during disease flare } \\
\text { plays an important role in increasing the serum Lp(a) levels in lupus patients with } \\
\text { renal disease and shows that corticosteroid treatment reduced the elevated serum } \\
\text { Lp(a) levels almost to original levels. }\end{array}$ \\
\hline SLE & Romero et al. 1999 [13] & $\begin{array}{l}\text { Existence of autoantibodies against MDA-Lp(a). The presence of antibodies } \\
\text { reacting not only against MDA-LDL but also against MDA-Lp (a) supports the } \\
\text { hypothesis of a role for oxidative phenomena in the pathogenesis of APS and } \\
\text { atherosclerosis. }\end{array}$ \\
\hline $\begin{array}{l}\text { SLE } \\
\text { autoimmune } \\
\text { disease }\end{array}$ & Sari et al. 2002 [3] & $\begin{array}{l}\text { Serum Lp(a) levels are significantly higher }(P<0.01) \text { in patients with SLE, these } \\
\text { patients have a risk of developing cardiovascular disease and atherosclerosis and } \\
\text { should be followed up. }\end{array}$ \\
\hline SLE & Zhang et al. 2010 [28] & $\begin{array}{l}\mathrm{Lp}(\mathrm{a})(400 \pm 213 \mathrm{mg} / \mathrm{L} \text { versus } 181 \pm 70 \mathrm{mg} / \mathrm{L}) \text { and ox-Lp(a) }(27.07 \pm 22.30 \mathrm{mg} / \mathrm{L} \\
\text { versus } 8.20 \pm 4.55 \mathrm{mg} / \mathrm{L}) \text { concentrations were higher in SLE patients than in } \\
\text { controls }(P<0.0001) . \text { Beta }(2)-G P I-L p(a) \text { complexes were detectable in both } \\
\text { controls and with higher levels in SLE patients. }\end{array}$ \\
\hline Immune & Borberg 2006 [54] & $\begin{array}{l}\mathrm{Lp}(\mathrm{a}) \text {-apheresis is available as a specific, highly efficient elimination procedure } \\
\text { superior to techniques which also eliminate } \mathrm{Lp}(\mathrm{a}) \text {. }\end{array}$ \\
\hline Immune & Milioti et al. 2008 [4] & $\begin{array}{l}\text { Antigenic stimuli in the pathogenesis of atherosclerosis: oxLDLs, } \\
\text { beta2glycoprotein } 1 \text { (beta2GP1), LP(a), heat shock proteins (HSPs), extracellular } \\
\text { matrix components (collagen and fibrinogen), and foreign antigens including } \\
\text { bacteria. }\end{array}$ \\
\hline $\begin{array}{l}\text { Autoimmune } \\
\text { disease }\end{array}$ & Jonasson et al. 1997 [1] & $\begin{array}{l}\text { Atherosclerosis, especially early onset coronary atherosclerosis, is not a disease } \\
\text { associated with particular HLA alleles. }\end{array}$ \\
\hline
\end{tabular}

[13]. The fact that $\operatorname{Lp}(\mathrm{a})$ is recognized as "antigen" might be a reaction to the changes it undergoes due to oxidation and glycosylation. This phenomenon was detected in APS and SLE patients as well.

Interestingly $\mathrm{Lp}(\mathrm{a})$ 's association with specific HLA-DR genotypes has been controversially discussed [1, 48]. Jonasson et al. [1] found no correlation between $\operatorname{Lp}(\mathrm{a})$ level and atherosclerosis and certain HLA genotypes in their investigation with 50 early onset atherosclerosis patients versus CAD patients. Dahlén [48] have shown an association for 30 patients between concurrent infectious disease and mean $\mathrm{Lp}(\mathrm{a})$ level. They suggest that an autoimmune process may especially occur in individuals with inherited high $\mathrm{Lp}(\mathrm{a})$ levels and certain HLA class II genotypes, triggered by a concurrent infection.

\subsection{Treatment Approaches and Recommendations}

4.1.1. Niacin. Nicotinic acid (1-3.0 g/day) reduces Lp(a) levels up to 35-40\% [49] and might be considered if, in addition to LDL-cholesterol lowering, decreases in triglycerides and $\mathrm{Lp}(\mathrm{a})$ and increases in HDL-cholesterol are aimed [26]. So far there is only one study investigating the effects of niacin as added on therapy versus atorvastatin alone on intima-mediathickness and Lp(a) level [50]. In 30 men with CHD and $\mathrm{Lp}(\mathrm{a})$ excess a regression of CIMT on an average of $0.06 \mathrm{~mm}$ 
in 6 months was shown. Additionally a reduction of $\mathrm{Lp}(\mathrm{a})$ from $84 \pm 40$ to $67 \pm 25 \mathrm{mg} / \mathrm{dL}$ occurred after 6 weeks and up to $65 \pm 37 \mathrm{mg} / \mathrm{dL}$ after 6 months of treatment, $P<0.01$. This is a hint that niacin might be useful in patients with elevated Lp(a) and CHD.

Niacin treatment alone or in combination with other lipid lowering agents showed cardiovascular benefits in several studies [51-53].

4.1.2. Lp(a)-Apheresis. Lp(a)-apheresis might be a promising therapeutic approach for patients with rare autoimmune diseases without treatment alternative, CVD progression and highly elevated $\operatorname{Lp}(\mathrm{a})$ levels $[54,55]$. Jaeger et al. [56] showed in a longitudinal, multicenter, cohort-study with 120 patients a median reduction of $\mathrm{Lp}(\mathrm{a})$ concentration from $4.00 \mathrm{micromol} / \mathrm{L}$ to $1.07 \mathrm{micromol} / \mathrm{L}$ with apheresis treatment $(P<0.0001)$. Hovland et al. [57] investigated in a recently published prospective cross-over study with 3 FH-patients the effect of weekly lipid apheresis with three different columns: DL-75, LA-15 and EC-50W on Lp(a) levels. They showed an average reduction of $\operatorname{Lp}(\mathrm{a})$ by $70 \%$, $74 \%$, and 75\% (all $P<0.0001$ ) for DL-75, LA-15 and EC$50 \mathrm{~W}$. Decision making of lipid apheresis should be based on CVD-progress, LDL cholesterol (LDL-C), or Lp(a) level if optimal conservative therapy is applied (lifestyle and maximal lipid-lowering drug therapy) [58].

4.1.3. Other Agents. New promising approaches contain thyroid hormone analogues, Apo-B-synthesis inhibitors, Farnesoid X receptor Agonists [59, 60], and CETP inhibitors-being currently under investigation.

\section{Conclusion}

We have shown an association between specific autoimmune disorders and elevated $\mathrm{Lp}(\mathrm{a})$ levels and the development of atherosclerosis. $\mathrm{Lp}(\mathrm{a})$ increase in autoimmune disease might play an important role as prognosis worsening risk factor of atherosclerosis and CHD.

Therefore it could be assumed that the $\operatorname{Lp}(\mathrm{a})$ measurement in patients with autoimmune disease is a worthwhile objective to investigate their atherosclerosis and CVD development risk.

\section{Conflict of Interests}

I. Missala and U. Kassner have both the same author's rights. The authors declare that they have no conflict of interests.

\section{References}

[1] L. Jonasson, T. Eriksson, G. H. Dahle'n, and B. Lindblom, "Lipoprotein(a) and HLA-DRB1 and -DQB1 genes in coronary artery disease," Atherosclerosis, vol. 133, no. 1, pp. 111$114,1997$.

[2] J. Frostegård, "Autoimmunity, oxidized LDL and cardiovascular disease," Autoimmunity Reviews, vol. 1, no. 4, pp. 233-237, 2002.
[3] R. A. Sari, M. F. Polat, S. Taysi, E. Bakan, and I. Çapoǧlu, "Serum Lipoprotein(a) level and its clinical significance in patients with systemic lupus erythematosus," Clinical Rheumatology, vol. 21, no. 6, pp. 520-524, 2002.

[4] N. Milioti, A. Bermudez-Fajardo, M. L. Penichet, and E. Oviedo-Orta, "Antigen-induced immunomodulation in the pathogenesis of atherosclerosis," Clinical and Developmental Immunology, vol. 2008, Article ID 723539, 15 pages, 2008.

[5] K. Berg, "A new serum type system in man-the lp system," Acta pathologica et microbiologica Scandinavica, vol. 59, pp. 369-382, 1963.

[6] K. A. Matthews, M. F. Sowers, C. A. Derby et al., "Ethnic differences in cardiovascular risk factor burden among middle-aged women: study of women's health across the nation (SWAN)," American Heart Journal, vol. 149, no. 6, pp. 1066-1073, 2005.

[7] S. Kiechl, J. Willeit, M. Mayr et al., "Oxidized phospholipids, lipoprotein(a), lipoprotein-associated phospholipase A2 Activity, and 10-year cardiovascular outcomes: prospective results from the bruneck study," Arteriosclerosis, Thrombosis, and Vascular Biology, vol. 27, no. 8, pp. 1788-1795, 2007.

[8] B. G. Nordestgaard, M. J. Chapman, K. Ray et al., "Lipoprotein(a) as a cardiovascular risk factor: current status," European Heart Journal, vol. 31, no. 23, pp. 2844-2853, 2010.

[9] G. Lippi, M. Franchini, and G. Targher, "Screening and therapeutic management of lipoprotein(a) excess: review of the epidemiological evidence, guidelines and recommendations," Clinica Chimica Acta, vol. 412, no. 11-12, pp. 797-801, 2011.

[10] G. C. Howard and S. V. Pizzo, "Lipoprotein(a) and its role in atherothrombotic disease," Laboratory Investigation, vol. 69, no. 4, pp. 373-386, 1993.

[11] F. I. Romero, M. A. Khamashta, and G. R. V. Hughes, "Lipoprotein(a) oxidation and autoantibodies: a new path in atherothrombosis," Lupus, vol. 9, no. 3, pp. 206-209, 2000.

[12] M. E. Haberland, G. M. Fless, A. M. Scanu, and A. M. Fogelman, "Malondialdehyde modification of lipoprotein(a) produces avid uptake by human monocyte-macrophages," The Journal of Biological Chemistry, vol. 267, no. 6, pp. 4143-4151, 1992.

[13] F. I. Romero, T. Atsumi, F.J. Tinahones et al., "Autoantibodies against malondialdehyde-modified lipoprotein(a) in antiphospholipid syndrome," Arthritis and Rheumatism, vol. 42, no. 12, pp. 2606-2611, 1999.

[14] S. Ylä-Herttuala, "Macrophages and oxidized low density lipoproteins in the pathogenesis of atherosclerosis," Annals of Medicine, vol. 23, no. 5, pp. 561-567, 1991.

[15] J. T. Salonen, S. Ylä-Herttuala, R. Yamamoto et al., "Autoantibody against oxidised LDL and progression of carotid atherosclerosis," The Lancet, vol. 339, no. 8798, pp. 883-887, 1992.

[16] E. Maggi, R. Bellazzi, A. Gazo, M. Seccia, and G. Bellomo, "Autoantibodies against oxidatively-modified LDL in uremic patients undergoing dialysis," Kidney International, vol. 46, no. 3, pp. 869-876, 1994.

[17] P. R. J. Ames, S. Lupoli, J. Alves et al., "The coagulation/fibrinolysis balance in systemic sclerosis: evidence for a haematological stress syndrome," British Journal of Rheumatology, vol. 36, no. 10, pp. 1045-1050, 1997.

[18] M. M. Cerinic, G. Valentini, G. G. Sorano et al., "Blood coagulation, fibrinolysis, and markers of endothelial dysfunction in systemic sclerosis," Seminars in Arthritis and Rheumatism, vol. 32, no. 5, pp. 285-295, 2003.

[19] A. M. Scanu and G. M. Fless, "Lipoprotein (a). Heterogeneity and biological relevance," Journal of Clinical Investigation, vol. 85, no. 6, pp. 1709-1715, 1990. 
[20] G. Lippi, P. Caramaschi, M. Montagnana, G. L. Salvagno, A. Volpe, and G. Guidi, "Lipoprotein[a] and the lipid profile in patients with systemic sclerosis," Clinica Chimica Acta, vol. 364, no. 1-2, pp. 345-348, 2006.

[21] Y. Asanuma, S. Kawai, H. Aoshima, J. Kaburaki, and Y. Mizushima, "Serum lipoprotein(a) and apolipoprotein(a) phenotypes in patients with rheumatoid arthritis," Arthritis and Rheumatism, vol. 42, no. 3, pp. 443-447, 1999.

[22] Y. H. Lee, S. J. Choi, J. D. Ji, H. S. Seo, and G. G. Song, "Lipoprotein(a) and lipids in relation to inflammation in rheumatoid arthritis," Clinical Rheumatology, vol. 19, no. 4, pp. 324-325, 2000.

[23] D. Dursunoğlu, H. Evrengül, B. Polat et al., "Lp(a) lipoprotein and lipids in patients with rheumatoid arthritis: serum levels and relationship to inflammation," Rheumatology International, vol. 25, no. 4, pp. 241-245, 2005.

[24] J. Wang, B. Hu, L. Kong, H. Cai, and C. Zhang, "Native, oxidized lipoprotein(a) and lipoprotein(a) immune complex in patients with active and inactive rheumatoid arthritis: plasma concentrations and relationship to inflammation," Clinica Chimica Acta, vol. 390, no. 1-2, pp. 67-71, 2008.

[25] G. Kerekes, Z. Szekanecz, H. Dér et al., "Endothelial dysfunction and atherosclerosis in rheumatoid arthritis: a multiparametric analysis using imaging techniques and laboratory markers of inflammation and autoimmunity," Journal of Rheumatology, vol. 35, no. 3, pp. 398-406, 2008.

[26] C. Zhang, X. Li, D. Niu et al., "Increased serum levels of $\beta_{2}$ GPI-Lp(a) complexes and their association with premature atherosclerosis in patients with rheumatoid arthritis," Clinica Chimica Acta, vol. 412, no. 15-16, pp. 1332-1336, 2011.

[27] M. McMahon, B. J. Skaggs, L. Sahakian et al., "High plasma leptin levels confer increased risk of atherosclerosis in women with systemic lupus erythematosus, and are associated with inflammatory oxidised lipids," Annals of the Rheumatic Diseases, vol. 70, no. 9, pp. 1619-1624, 2011.

[28] C. Zhang, K. Li, B. Shi et al., "Detection of serum $\beta_{2}$-GPI$\mathrm{Lp}$ (a) complexes in patients with systemic lupus erythematosus," Clinica Chimica Acta, vol. 411, no. 5-6, pp. 395-399, 2010.

[29] M. Okawa-Takatsuji, S. Aotsuka, M. Sumiya, H. Ohta, M. Kawakami, and I. Sakurabayashi, "Clinical significance of the serum lipoprotein(a) level in patients with systemic lupus erythematosus: its elevation during disease flare," Clinical and Experimental Rheumatology, vol. 14, no. 5, pp. 531-536, 1996.

[30] E. Kiss, B. Fazekas, T. Tarr, L. Muszbek, M. Zeher, and G. Szegedi, "Examination of lipid profile in patients with systemic lupus erythematosus: With a special focus on lipoprotein (a) in lupus nephritis," Orvosi Hetilap, vol. 145, no. 5, pp. 217222, 2004.

[31] S. Rantapää-Dahlqvist, G. Neumann-Andersen, C. Backman, G. Dahlén, and B. Stegmayr, "Echocardiographic findings, lipids and lipoprotein(a) in patients with systemic lupus erythematosus," Clinical Rheumatology, vol. 16, no. 2, pp. 140$148,1997$.

[32] C. Wanner, D. Rader, W. Bartens et al., "Elevated plasma lipoprotein(a) in patients with the nephrotic syndrome," Annals of Internal Medicine, vol. 119, no. 4, pp. 263-269, 1993.

[33] T. Fujita, E. Saito, H. Ohi, T. Yasugi, and M. Hatano, "Lipoprotein(a) predicts the risk of thrombogenic complications in nephrotic syndrome," Nephron, vol. 61, no. 1, article 122, 1992.

[34] J. Matsuda, K. Gohchi, and K. Kawasugi, "Increased factor VIIa levels in systemic lupus erythematosus patients with lupus anticoagulant," International Journal of Hematology, vol. 65, no. 2, pp. 143-149, 1997.
[35] G. R. V. Hughes, "The antiphospholipid syndrome: ten years on," The Lancet, vol. 342, no. 8867, pp. 341-344, 1993.

[36] T. Atsumi, M. A. Khamashta, C. Andujar et al., "Elevated plasma lipoprotein(a) level and its association with impaired fibrinolysis in patients with antiphospholipid syndrome," Journal of Rheumatology, vol. 25, no. 1, pp. 69-73, 1998.

[37] M. Yamazaki, H. Asakura, H. Jokaji et al., "Plasma levels of lipoprotein(a) are elevated in patients with the antiphospholipid antibody syndrome," Thrombosis and Haemostasis, vol. 71, no. 4, pp. 424-427, 1994.

[38] M. Bećarević, S. Singh, and N. Majkić-Singh, "Lipoprotein (a) and apolipoprotein (a) in primary antiphospholipid syndrome," Clinical Biochemistry, vol. 40, no. 5-6, pp. 317-320, 2007.

[39] H. Kritz, J. Pidlich, J. O'Grady, and H. Sinzinger, "Is $\mathrm{a}(\mathrm{n}$ inborn) deficiency of prostacyclin synthesis stimulating plasma factor associated with increased lipoprotein(a)?" Prostaglandins Leukotrienes and Essential Fatty Acids, vol. 55, no. 5, pp. 363-372, 1996.

[40] S. Yasuda, A. Tsutsumi, H. Chiba et al., “ $\beta 2$-glycoprotein I deficiency: prevalence, genetic background and effects on plasma lipoprotein metabolism and hemostasis," Atherosclerosis, vol. 152, no. 2, pp. 337-346, 2000.

[41] F. López-Lira, L. Rosales-León, V. M. Martínez, and B. H. Ruiz Ordaz, "The role of $\beta 2$-glycoprotein I ( $\left.\beta_{2} \mathrm{GPI}\right)$ in the activation of plasminogen," Biochimica et Biophysica Acta, vol. 1764, no. 4, pp. 815-823, 2006.

[42] J. J. Wang, J.-B. Gong, H. Li et al., "Lipoprotein(a) complexes with Beta2-Glycoprotein I in patients with coronary artery disease," Journal of Atherosclerosis and Thrombosis, vol. 19, no. 1, pp. 81-89, 2012.

[43] H. Wehr, M. Rado, T. Mendel, M. Swiderska, M. BednarskaMakaruk, and W. Szirkowiec, "Changes in lipoprotein (a) [Lp(a)] level after an ischemic stroke," Neurologia i Neurochirurgia Polska, vol. 38, no. 3, pp. 197-200, 2004.

[44] H. J. Milionis, V. Mittari, G. Exarchakos, R. Kalaitzidis, A. T. Skevas, and M. S. Elisaf, "Lipoprotein (a) and acute-phase response in patients with vestibular neuronitis," European Journal of Clinical Investigation, vol. 33, no. 12, pp. 1045-1050, 2003.

[45] V. Topçu-Shufta, L. Begolli, and E. Kryeziu, "Lipoprotein (a) as an acute phase reactant in patients on chronic hemodialysis," Bosnian Journal of Basic Medical Sciences, vol. 10, no. 1, pp. 19-25, 2010.

[46] K. Kario, T. Matsuo, H. Kobayashi, M. Matsuo, R. Asada, and M. Koide, "High lipoprotein (a) levels in chronic hemodialysis patients are closely related to the acute phase reaction," Thrombosis and Haemostasis, vol. 74, no. 4, pp. 1020-1024, 1995.

[47] S. Wållberg-Jonsson, A. Uddhammar, G. Dahlén, and S. Rantapää-Dahlqvist, "Lipoprotein(a) in relation to acute phase reaction in patients with rheumatoid arthritis and polymyalgia rheumatica," Scandinavian Journal of Clinical and Laboratory Investigation, vol. 55, no. 4, pp. 309-315, 1995.

[48] G. H. Dahlén, "Lp(a) lipoprotein in cardiovascular disease," Atherosclerosis, vol. 108, no. 2, pp. 111-126, 1994.

[49] L. A. Carlson, A. Hamsten, and A. Asplund, "Pronounced lowering of serum levels of lipoprotein $\mathrm{Lp}(\mathrm{a})$ in hyperlipidaemic subjects treated with nicotinic acid," Journal of Internal Medicine, vol. 226, no. 4, pp. 271-276, 1989.

[50] M. S. Safarova, E. P. Trukhacheva, M. V. Ezhov et al., "Pleiotropic effects of nicotinic acid therapy in men with coronary heart disease and elevated lipoprotein(a) levels," Kardiologiia, vol. 51, no. 5, pp. 9-16, 2011. 
[51] L. Cashin-Hemphill, W. J. Mack, J. M. Pogoda, M. E. Sanmarco, S. P. Azen, and D. H. Blankenhorn, "Beneficial effects of colestipol-niacin on coronary atherosclerosis. A 4-year follow-up," The Journal of the American Medical Association, vol. 264, no. 23, pp. 3013-3017, 1990.

[52] A. Goldberg, P. Alagona, D. M. Capuzzi et al., "Multipledose efficacy and safety of an extended-release form of niacin in the management of hyperlipidemia," American Journal of Cardiology, vol. 85, no. 9, pp. 1100-1105, 2000.

[53] A. J. Taylor, T. C. Villines, E. J. Stanek et al., "Extended-release niacin or ezetimibe and carotid intima-media thickness," The New England Journal of Medicine, vol. 361, no. 22, pp. 2113 2122, 2009.

[54] H. Borberg, "Quo vadis haemapheresis: current developments in haemapheresis," Transfusion and Apheresis Science, vol. 34, no. 1, pp. 51-73, 2006.

[55] S. Sakata, T. Komaki, and N. Kojima, "Dynamics of plasma lipoproteins and lipids during double filtration plasmapheresis (DEP)," Japanese Journal of Medicine, vol. 26, no. 2, pp. 176-179, 1987.

[56] B. R. Jaeger, Y. Richter, D. Nagel et al., "Longitudinal cohort study on the effectiveness of lipid apheresis treatment to reduce high lipoprotein(a) levels and prevent major adverse coronary events," Nature Clinical Practice Cardiovascular Medicine, vol. 6, no. 3, pp. 229-239, 2009.

[57] A. Hovland, S. Marcovina, R. Hardersen, T. Enebakk, T. E. Mollnes, and K. T. Lappegård, "Three different LDL apheresis columns efficiently and equally reduce lipoprotein(a) concentrations in patients with familial hypercholesterolemia and small apolipoprotein(a) particles," Transfusion and Apheresis Science, vol. 46, no. 1, pp. 73-76, 2012.

[58] U. Kassner, A. Vogt, A. Rosada et al., "Designing a study to evaluate the effect of apheresis in patients with elevated lipoprotein(a)," Atherosclerosis Supplements, vol. 10, no. 5, pp. 8588, 2009.

[59] I. Chennamsetty, T. Claudel, K. M. Kostner et al., "Farnesoid $\mathrm{X}$ receptor represses hepatic human APOA gene expression indumathi chennamsetty," Journal of Clinical Investigation, vol. 121, no. 9, pp. 3724-3734, 2011.

[60] A. Mencarelli and S. Fiorucci, "FXR an emerging therapeutic target for the treatment of atherosclerosis," Journal of Cellular and Molecular Medicine, vol. 14, no. 1-2, pp. 79-92, 2010.

[61] N. Busso, J. Dudler, R. Salvi et al., "Plasma apolipoprotein(a) co-deposits with fibrin in inflammatory arthritic joints," American Journal of Pathology, vol. 159, no. 4, pp. 1445-1453, 2001.

[62] M. Cesur, Z. Ozbalkan, M. A. Temel, and Y. Karaarslan, "Ethnicity may be a reason for lipid changes and high Lp(a) levels in rheumatoid arthritis," Clinical Rheumatology, vol. 26, no. 3, pp. 355-361, 2007.

[63] S. H. Zrour, F. H. Neffeti, N. Sakly et al., "Lipid profile in Tunisian patients with rheumatoid arthritis," Clinical Rheumatology, vol. 30, no. 10, pp. 1325-1331, 2011.

[64] Y. B. Park, S. K. Lee, W. K. Lee et al., "Lipid profiles in untreated patients with rheumatoid arthritis," The Journal of Rheumatology, vol. 26, no. 8, pp. 1701-1704, 1999.

[65] S. Rantapää-Dahlqvist, G. Neumann-Andersen, C. Backman, G. Dahlén, and B. Stegmayr, "Echocardiographic findings, lipids and lipoprotein(a) in patients with systemic lupus erythematosus," Clinical Rheumatology, vol. 16, no. 2, pp. 140$148,1997$.

[66] O. Schultz, F. Oberhauser, J. Saech et al., "Effects of inhibition of interleukin- 6 signalling on insulin sensitivity and lipoprotein (a) levels in human subjects with rheumatoid diseases," PLoS ONE, vol. 5, no. 12, Article ID e14328, 2010.

[67] E. F. Borba, R. D. Santos, E. Bonfa et al., "Lipoprotein(a) levels in systemic lupus erythematosus," The Journal of Rheumatology, vol. 21, no. 2, pp. 220-223, 1994.

[68] J. George, B. Gilburd, P. Langevitz et al., “ $\beta 2$ glycoprotein I containing immune-complexes in lupus patients: association with thrombocytopenia and lipoprotein (a) levels," Lupus, vol. 8, no. 2, pp. 116-120, 1999. 


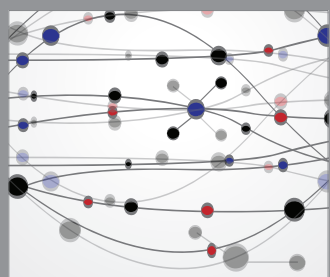

The Scientific World Journal
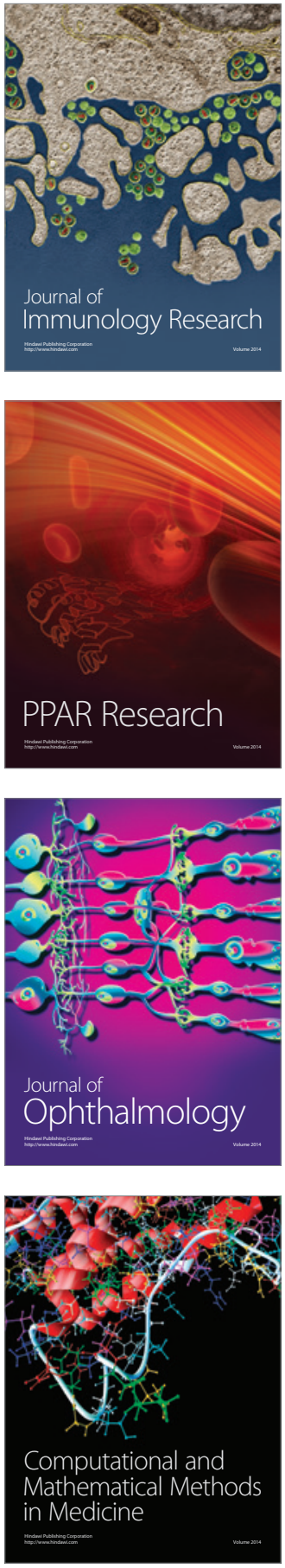

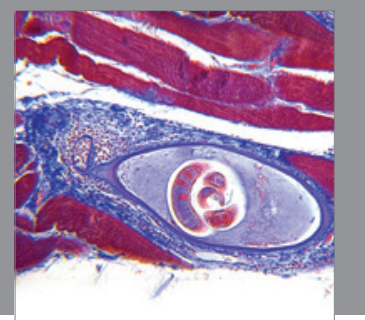

Gastroenterology

Research and Practice
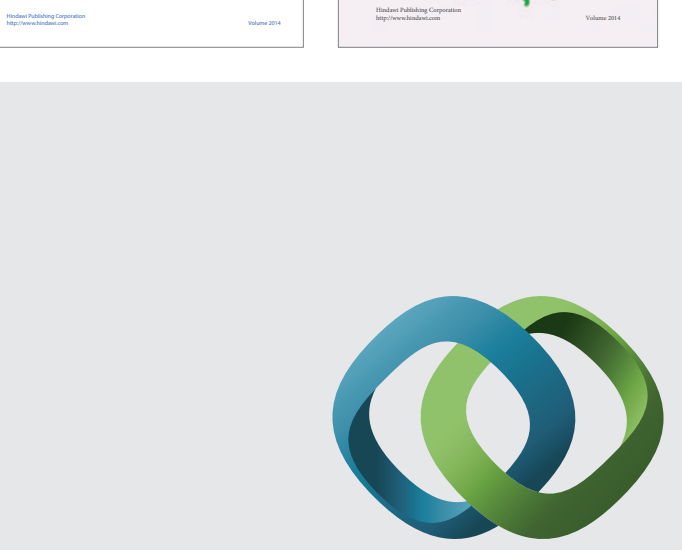

\section{Hindawi}

Submit your manuscripts at

http://www.hindawi.com
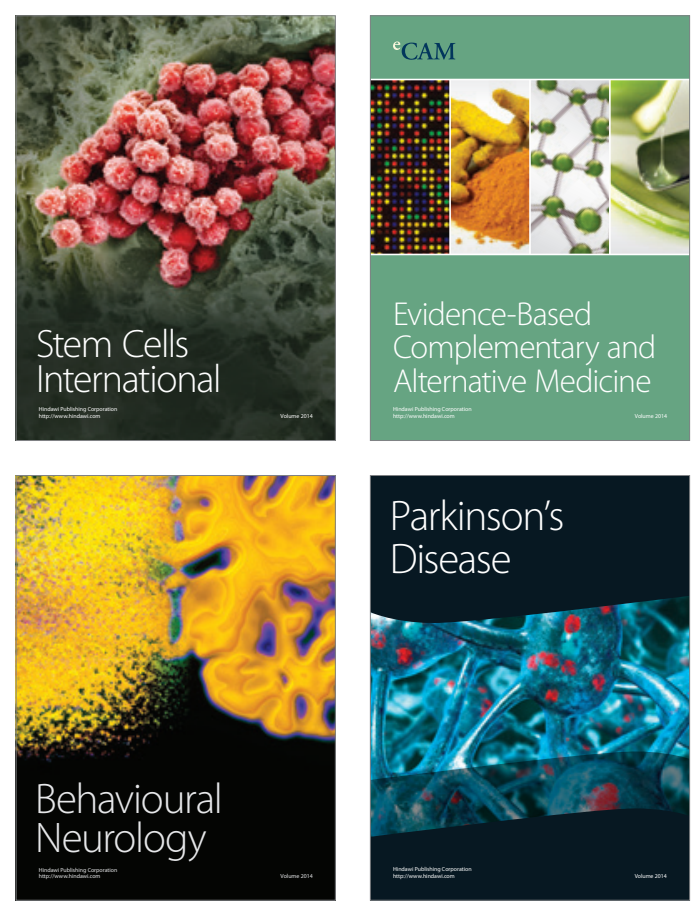

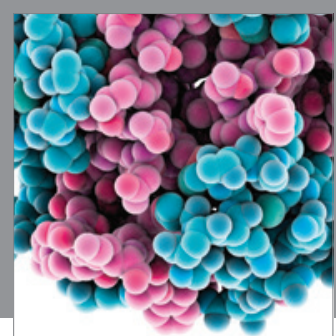

Journal of
Diabetes Research

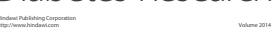

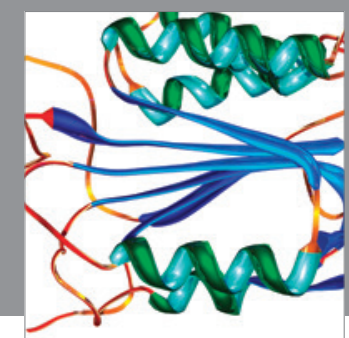

Disease Markers
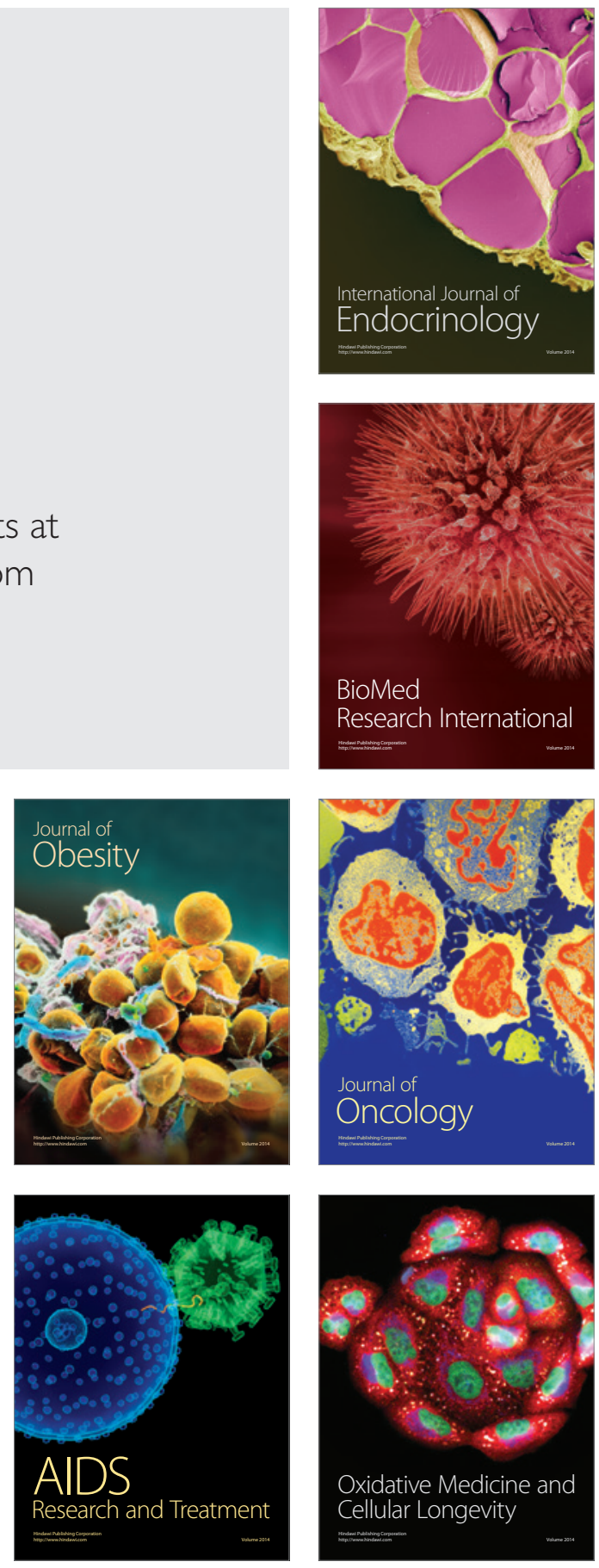